\title{
Human Papillomavirus Infection and Cervical Cancer in Brazil: a Retrospective Study
}

\author{
Sílvia MB Cavalcanti/ ${ }^{+}$, Flávia CC Deus, Lucília G Zardo*, \\ Izabel CPP Frugulhetti, Ledy HS Oliveira
}

\begin{abstract}
Departamento de Microbiologia e Parasitologia, Instituto Biomédico, Universidade Federal Fluminense, Rua Ernani Melo 101, 24210-030 Niterói, RJ, Brasil * Setor de Anatomia Patológica e Citopatologia, Hospital Luíza Gomes de Lemos, Instituto Nacional de Câncer, Rua Visconde de Santa Isabel 274, 20560-120

Rio de Janeiro, RJ, Brasil
\end{abstract}

Two hundred and thirty paraffin-embedded biopsies obtained from female cervical lesions were tested for the presence of human papillomavirus (HPV) types 6/11,16/18 and 31/33/35 DNA using nonisotopic in situ hybridization. Specimens were classified according to the Bethesda System in low grade squamous intraepithelial lesion (LSIL), high grade SIL (HSIL) and squamous cell carcinoma (SCC). HPV prevalence ranged from $92.5 \%$ in LSIL to $68.5 \%$ in SCC. Benign types were prevalent in LSILs while oncogenic types infected predominantly HSILs and SCC. HPV infection showed to be age-dependent, but no significant relation to race has been detected. Patients were analyzed through a five-year period: $20.7 \%$ of the lesions spontaneously regressed while $48.9 \%$ persisted and $30.4 \%$ progressed to carcinoma. Patients submitted to treatment showed a $19.4 \%$ recurrence rate. High risk types were present in $78.6 \%$ (CrudeOR 13.8, $P=0.0003$ ) of the progressive lesions, and in $73.7 \%$ of the recurrent SILs (COR 19.3, $P=0.0000001)$. Possible co-factors have also been evaluated: history of other sexually transmitted diseases showed to be positively related either to progression (Adjusted OR 13.0, $P=0.0002$ ) or to recurrence (AOR 17.2, $P=0.0002$ ) while oral contraceptive use and tobacco smoking were not significantly related to them $(P>0.1)$. Association of two or more co-factors also proved to be related to both progression and recurrence, indicating that they may interact with HPV infection in order to increase the risk of developing malignant lesions.

Key words: human papillomavirus - progression - risk factors - cervical cancer

Experimental and epidemiological data have been accumulated to support a central role for human papillomavirus (HPV) in the aetiology of anogenital cancer, specially cervical carcinoma (Schiffman 1994). Nearly 70 different types of HPV have now been described, and 28 have been isolated from benign and malignant genital lesions (De Villiers 1989). These viruses have been further classified according to their malignant potential. High risk types (e.g. HPV16,18 and to a lesser extent 31,33 and 35) have been linked to high grade intraepithelial lesions (HSILs) and invasive carcinoma, whereas low risk types (e.g. HPV6 and 11) have been associated to benign or low grade SILs (LSILs). Differences in oncogenic potential of low and high risk types were also demonstrated by transformation experiments (Woodworth et al. 1989).

Work supported by CNPq.

${ }^{+}$Corresponding author. Fax: 55-21-719.2588

Received 2 October 1995

Accepted 11 April 1996
Cervical carcinogenesis is a multi-step process in which certain factors are thought to be required for the HPV-induced lesions to progress (Roman $\&$ Fife 1989). Cigarette smoking, oral contraceptive use and concurrent sexually transmitted diseases (STD) may be such co-factors. The elucidation of their role in this malignant process leads to the possibility of distinguishing the HPV infected women at increased risk for progression to cancer from those eventually regressing without treatment, what may affect the assessment of the prognosis, the choice of treatment and the follow-up modalities.

Cervical cancer is the second leading cause of cancer deaths in women world-wide. In many developing countries, it is still the main cause of death from cancer in women (Lowy et al. 1994). In Brazil, high annual cancer incidences have been reported. Nevertheless, there have been few published epidemiological studies concerning the prevalence of HPV DNA in the female genital tract and the natural history of the infection.

The aim of our study was to determine the prevalence of different HPV types in squamous intraepithelial lesions of the cervix of Brazilian 
women and to search for specific risk factors associated with progression to malignancy and with post-treatment recurrence.

\section{MATERIALS AND METHODS}

Specimens - The material of the present study includes a series of 230 cases of normal, benign, premalignant and malignant cervical biopsies of women attended at Hospital Luíza Gomes de Lemos, State of Rio de Janeiro, from 1989 to 1994. Patients were selected within a group referred to histopathologic examination after an altered cytology (Pap smear). The follow-up period was six years, with intervals of six months, in average. The medical records of all investigated patients were reviewed for possible risk factors and previously diagnosed STDs, including HIV infection, genital herpes, gonorrhoea, chlamydial infection, bacterial pelvic inflammatory disease, thrichomoniasis and syphilis. Forty-two percent of the patients were treated: partial ablation with diathermy and electrocauterization were used for LSILs and conization was the treatment of choice for HSILs. Patients left untreated were those who did not come back for treatment and/or for preventive exam, so their follow-up intervals were longer than for treated patients. Formalin-fixed, paraffin-embedded biopsy specimens were available for studies in the files of the Department of Pathology. Five $\mu \mathrm{m}$ sections were cut onto Aminopropyl triethoxysilane (Sigma) coated slides, heated at $60^{\circ} \mathrm{C}$ for $2 \mathrm{hr}$ and stored at room temperature (RT).

Histological diagnosis - Slides were stained with haematoxylin and eosin (HE) for grading of the cervical lesions according to the Bethesda System (1993) in LSIL, including condylomata and cervical intraepithelial neoplasia grade I (CIN I), in HSIL, including CIN II and CIN III/ in situ carcinoma, and in squamous cell carcinoma (SCC). Histologically normal tissues presenting only reactive/reparative changes were classified as Reactive Changes (RC).

Probes - HPV 6b, 11, 16 and 18 DNAs were kindly provided by Dr De Villiers (Heidelberg). They were prepared and purified through caesiumchloride gradients. Plasmids were labelled using a nick translation kit (BRL) and biotin-11-d UTP (Sigma). HPV 31, 33 and 35 DNAs were available in Digene In situ Hybridization Kit.

In situ hybridization (ISH) - ISH procedure has been described in detail elsewhere (Cavalcanti et al. 1994). Briefly, sections have been deparaffinized in two changes of xylol and two changes of $100 \%$ ethanol. Nucleic acids were unmasked by digestion with $0.5 \mathrm{mg} / \mathrm{ml}$ proteinase $\mathrm{K}$ (Sigma). The hybridization mixture contained 5xSSC, $5 \%$ polyethileneglycol, $0.1 \mathrm{mg} / \mathrm{ml}$ dena- tured carrier DNA (herring sperm), biotinylated probes $(1.0 \mu \mathrm{g} / \mathrm{ml})$ and $50 \%$ deionized formamide. Each section was layered with $20 \mu$ of hybridization mixture under a coverslip, denatured by heating at $92^{\circ} \mathrm{C}$ for $10 \mathrm{~min}$ on a heating block, and hybridized at $37^{\circ} \mathrm{C}$ for $2 \mathrm{hr}$. Coverslips have been removed by soaking the slides in 4xSSC at RT for 10 min. Further the slides have been washed in $0.1 \times \mathrm{xSC} / 50 \%$ formamide, $4 \mathrm{xSSC}$ and phosphate buffered saline $\mathrm{pH} 7.2$ (PBS) at RT for $10 \mathrm{~min}$ each.

The DNA-DNA hybrids were visualized by using streptavidin-alkaline phosphatase complex at RT for $30 \mathrm{~min}$. Unbound conjugate has been removed by two washes in Buffer $1(0.1 \mathrm{M}$ Tris $\mathrm{HCl}, 0.15 \mathrm{M} \mathrm{NaCl}, \mathrm{pH} 7.5$ ) for $10 \mathrm{~min}$ and once in Buffer $3(0.1 \mathrm{M}$ Tris $\mathrm{HCl}, 0.1 \mathrm{M} \mathrm{NaCl}, 50 \mathrm{mM}$ $\mathrm{MgCl}_{2}, \mathrm{pH} 9.5$ ) for $5 \mathrm{~min}$ at $\mathrm{RT}$. The slides have then been incubated in NBT (nitroblue tetrazolium) and BCIP (5-bromo-4-chloro-3-indolylphosphate) dissolved in Buffer 3 at RT for 30 min in the dark. Slides have been rinsed in distilled water to stop reaction, air dried and mounted in glycerine jelly without counterstaining. This method is meant to be capable of detecting approximately 50 to 100 viral genome copies per cell. Positive cells are detected by strong nuclear signal in the upper epithelial layers especially when associated with koilocytic features. Occasional intermediate and parabasal cells with or without koilocytosis also show a purple precipitate in the nuclei under light microscopy (Syrjanen 1990).

HPV-positive and negative cervical biopsies have been used as controls in every experiment. They were composed by 3 RC, 4 LSIL, 4 HSIL and $1 \mathrm{SCC}$ and have been previously tested by Southern blot followed by hybridization onto nytrocellulose membrane (data not shown). These controls have also been submitted to HPV detection by using type specific primers in PCR (Table III).

Polymerase Chain Reaction (PCR) - Briefly, $10 \mu \mathrm{m}$ sections were cut from the paraffin blocks, deparaffinized in octane and added to $150 \mu \mathrm{l}$ of digestion buffer $(50 \mathrm{mM}$ Tris- $\mathrm{HCl} \mathrm{pH} 8.5,10 \mathrm{mM}$ EDTA, $200 \mu \mathrm{g} / \mathrm{ml}$ proteinase $\mathrm{K}$ - final concentration of $100 \mu \mathrm{g} / \mathrm{ml}$ ) for $18 \mathrm{hr}$ at $37^{\circ} \mathrm{C} .100 \mu \mathrm{l} \mathrm{PCR}$ reaction mixture containing 2.5 units of Taq polymerase have been prepared and subjected to 40 cycles of amplification. Cycles were carried out using the following method: denaturation at $92^{\circ} \mathrm{C}$ for $1 \mathrm{~min}$, annealing at $55^{\circ} \mathrm{C}$ for $2 \mathrm{~min}$, extension at $72^{\circ} \mathrm{C}$ for $2 \mathrm{~min}$, ending at $72^{\circ} \mathrm{C}$ for $10 \mathrm{~min}$.

Primers used have kindly been given by $\mathrm{Dr}$ Villa (Ludwig Institute for Cancer Research - São Paulo, Brazil) and allowed amplification of a region within the E1 open reading frame of HPV $6,11,16,18,31,33,35$ giving products with 89 to 230bp (Young et al. 1989). PCR products have 
been identified by size determination in $12 \%$ polyacrylamide gel stained with ethidium bromide. Various concentrations of purified cloned DNA of HPV 6 and 16, DNA from CaSki and HeLa cells, containing HPV 18 and 16 genomes, respectively, were used as positive controls. To analyze the quality of target DNA, samples have been subjected to PCR using $\beta$-globin gene specific primers (Vandenvelde et al. 1990).

Statistical analysis - The statistical significance of the results has been analyzed by using the chisquare test for heterogeneity with Yates continuity correction, Fisher's exact test and a MantelHaentszel procedure for trend, when appropriate. Multivariate logistic regression analysis was performed to examine the associations of progression/ regression and recurrence/cure and various risk factors simultaneously. Odds ratios were used as a measure of association. All analyses were done using Epi Info (version 5) microcomputer software (USD, Stone Mountain, GA).

\section{RESULTS}

Two hundred and thirty biopsies from female cervical lesions have been investigated to detect the presence of HPV DNA. The average age of participants was 38.7 years, ranging from 16 to 75 years old. The studied population was composed of $128(59.5 \%)$ white, 57 (26.5\%) mulatto and 30 $(14.0 \%)$ African origin women.

No significant correlation has been found for HPV infection and race $(P>0.1)$. Although a higher number of white women presenting cervical lesions were studied, HPV infection rates were similar within the three studied groups (Fig.). Different age distribution patterns have been shown according to the histological grade of the HPV infected lesions: the LSIL group $\left(\mathrm{X}_{\text {age }}=31.5\right)$ exhibit statistically significant differences when compared to the malignant $\operatorname{SCC}\left(\mathrm{X}_{\mathrm{age}}=46.9, \mathrm{P}<0.001\right)($ Table I).

As shown in Table II, the overall prevalence of HPV DNA in the studied group was $73.9 \%$ (170/ $230)$ ranging from $92.5 \%$ (49/53) in LSIL to $68.5 \%$

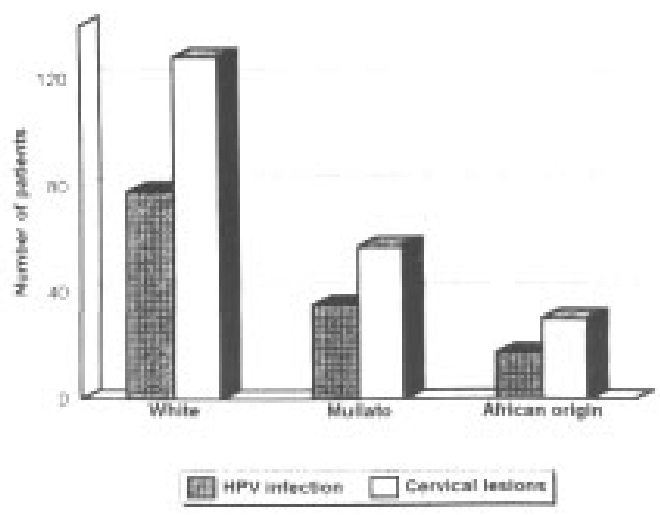

HPV infection in cervical lesions of women of different races.

TABLE I

Average age of $\mathrm{HPV}^{a}$ infected women according to the histological grade of lesions

\begin{tabular}{ccccc}
\hline & \multicolumn{4}{c}{ Histological diagnosis of patients } \\
\cline { 2 - 5 } & $\begin{array}{c}\text { Reactive Changes LSIL } \\
(\mathrm{n}=3)\end{array}$ & $\begin{array}{c}\text { HSIL } \\
(\mathrm{n}=49)\end{array}$ & $\begin{array}{c}\text { SCC } \\
(\mathrm{n}=81)\end{array}$ & $(\mathrm{n}=37)$ \\
\cline { 2 - 5 } & 34.6 & 31.5 & 36.7 & 46.9 \\
\hline
\end{tabular}

$a$ : HPV 6, 11, 16, 18, 31, 33 and 35 .

(37/54) in SCC. The control group (RC) presented $15.0 \%$ (3/20) of HPV positivity. Statistically significant differences have been detected among the cervical lesions and the control $(\mathrm{RC})(\mathrm{P}<0.0001)$ for HPV infection of the cervix.

Prevalences of different HPV types are shown in Table II. In the LSILs, HPV 6/11 were the most prevalent types (61.2\%). In the HSILs, HPV 16/ 18 prevailed over the others $(40.7 \%)$ as well as in the SCC, where HPV 16/18 prevalence was also the highest one (56.8\%). HPV 31/33/35 were frequently found in both HSILs $(19.8 \%)$ and SCC $(29.7 \%)$. Thirty-eight out of $170(22.4 \%)$ HPV positive lesions showed mixed infections.

\section{TABLE II}

Prevalence of different human papillomavirus types according to the histological diagnosis

\begin{tabular}{|c|c|c|c|c|c|c|c|}
\hline \multirow[t]{2}{*}{ Diagnosis } & \multirow{2}{*}{$\begin{array}{l}\text { Number of } \\
\text { patients }\end{array}$} & \multicolumn{4}{|c|}{ HPV types } & \multirow{2}{*}{\multicolumn{2}{|c|}{$\begin{array}{c}\text { HPV prevalence } \\
(\%)\end{array}$}} \\
\hline & & $6 / 11$ & $16 / 18$ & $31 / 33 / 35$ & mixed & & \\
\hline Reactive changes & 20 & 2 & - & 1 & - & 3 & $(15.0) \%$ \\
\hline LSIL & 53 & 30 & 4 & 2 & $13^{a}$ & 49 & $(92.5 \%)$ \\
\hline HSIL & 103 & 11 & 33 & 16 & $21^{b}$ & 81 & $(78.6 \%)$ \\
\hline SCC & 54 & 1 & 21 & 11 & $4^{c}$ & 37 & $(68.5 \%)$ \\
\hline Total & 230 & 44 & 58 & 30 & 38 & 170 & $(73.9 \%)$ \\
\hline
\end{tabular}

$a: 10$ HPV 6/11, 16/18; 3 HV 6/11, 31/33/35; $b$ : 12 HPV 6/11, 16/18; 9 HPV 16/18, 31/33/35; $c$ : 2 HPV 6/11, 16/ 18; 1 HPV 16/18, 31/33/35; 1 HPV 6/11,16/18, 31/33/35. 
PCR results for the 12 tested controls were nearly the same obtained by in situ hybridization (Table III), except for one sample that PCR revealed to be a double infection by HPV16 and 33, and ISH had only indicated the presence HPV16 DNA. No other differences in sensibility or specificity have been detected.

The retrospective analysis showed that from 1989 to 1994 , in $20.7 \%$ (19/92) of the untreated patients HPV-induced lesions regressed spontaneously, in $48.9 \%$ (45/92) the lesion persisted and in $30.4 \%$ (28/92) the lesion showed clinical progression to in situ carcinoma or to invasive cancer. Spontaneously regressing cases presented low risk HPVs $6 / 11$ in $68.4 \%$ of the lesions, showing to be inversely related to progression (Crude OR 0.02, $\mathrm{P}=0.000009)$, what means directly related to regression $\left(X^{2}=19.7, P=0.000009\right)$ while persisting and progressive cases showed high risk types in $63.3 \%$ and $78.6 \%$ of the samples, respectively. Oncogenic HPV types $16 / 18$ were strongly associated with progression (COR 13.8, $\mathrm{P}=0.0003$ ), while HPVs types $31 / 33 / 35$ did not show significant correlation (COR 1.8, $\mathrm{P}=0.7)$.

Co-factors currently related to cancer progression in HPV infected women have been investigated. From patients with progressive lesions, $42.9 \%(12 / 28)$ were tobacco smokers, $75 \%$ showed other STD (21/28) and 35.7\% (10/28) used oral contraceptive regularly. From women showing spontaneous regression, $26.3 \%$ (5/19) were smokers, $15.8 \%$ (3/19) had other STD and 26.3\% (5/ 19) used oral contraceptives. After adjustment for age, race, and HPV types, the presence of concurrent STDs showed to be significantly related to malignant evolution (Adjusted OR 13.0, $\mathrm{P}=0.0002)$. Cigarette smoking and oral contraceptive (OC) use presented approximately the same rates for progressive and regressing lesions, and thus were not associated to progression (AOR 1.8 and 1.4, respectively, with $\mathrm{P}>0.1$ ) for both. Data are presented in Table IV.

From the 230 studied women, 98 were treated. Partial ablation with diathermy and electrocauterization were the treatments of choice for LSILs, while conization was the procedure applied for HSILs. After treatment, 19 patients (19.4\%) showed recurrence, but none of them presented lesion progression in the follow-up period. As shown in Table V, 14 of the recurrent lesions (73.7\%) presented oncogenic HPV DNA, with significant association of recurrence and HPV types 16/18 (COR19.3, $\mathrm{P}=0.000001$ ). Analysis of recurrence rates in treated women pointed out that $31.6 \%$ (6/19) of the patients showing recurrence presented other STDs, comparing to the cured cases $(2.5 \%$, $2 / 79$ ) and statistically significant difference was detected (AOR 17.2, $\mathrm{P}=0.0002$ ). No other factor, such as cigarette smoking or OC use, presented significant role in differentiating recurrent from cured lesions $(\mathrm{P}>0.5)$.

\section{DISCUSSION}

In our study, 170 out of $230(73.9 \%)$ cervical biopsies were infected by HPV. Similar prevalence rates have been described previously, even when diverse detection systems were used (Syrjanen 1989, Kiviat et al. 1989): 44 biopsies (25.9\%) contained HPV6/11, 58 (34.1\%) contained HPV16/18 and $30(17.6 \%)$ contained HPV31/33/35. Oncogenic HPV 16 and 18 were the most common types in malignant lesions, showing an upward trend with high statistical significance from LSIL to SCC (Table II, $\mathrm{P}<0.0002$ ). Low risk HPV 6 and 11 do not seem to play an important role in carcinogenesis, since their prevalences tended to decrease significantly from LSIL to SCC ( $\mathrm{P}<0.00001)$. It is also worth noting that HPV6 and 11 have not been found in the premalignant and malignant lesions, except when in mixed infec-

\section{TABLE III}

Comparison of human papillomavirus typing by in situ hybridization (ISH) and the polymerase chain reaction (PCR)

\begin{tabular}{cccccccc}
\hline HPV types & \multicolumn{9}{c}{ HPV types by ISH } & Total \\
\cline { 2 - 6 } by PCR & 6 & 11 & 16 & 18 & Mixed & Negative & \\
\hline \multirow{2}{*}{6} & 4 & - & - & - & - & - & 4 \\
11 & - & - & - & - & - & - & - \\
16 & - & - & 2 & - & - & - & 2 \\
18 & - & - & - & - & - & - & - \\
Mixed & - & - & $1^{a}$ & - & $2^{b}$ & - & 3 \\
Negative & - & - & - & - & - & 3 & 3 \\
\hline Total & 4 & - & 3 & - & 2 & 3 & 12 \\
\hline
\end{tabular}

a: PCR mixed infection: HPV 16 and 33; ISH: HPV 16; $b$ : PCR and ISH mixed infection: 2 HPV 6,16. 
TABLE IV

Risk factors associated to progression of Low Squamous Intraepithelial Lesions to cancer

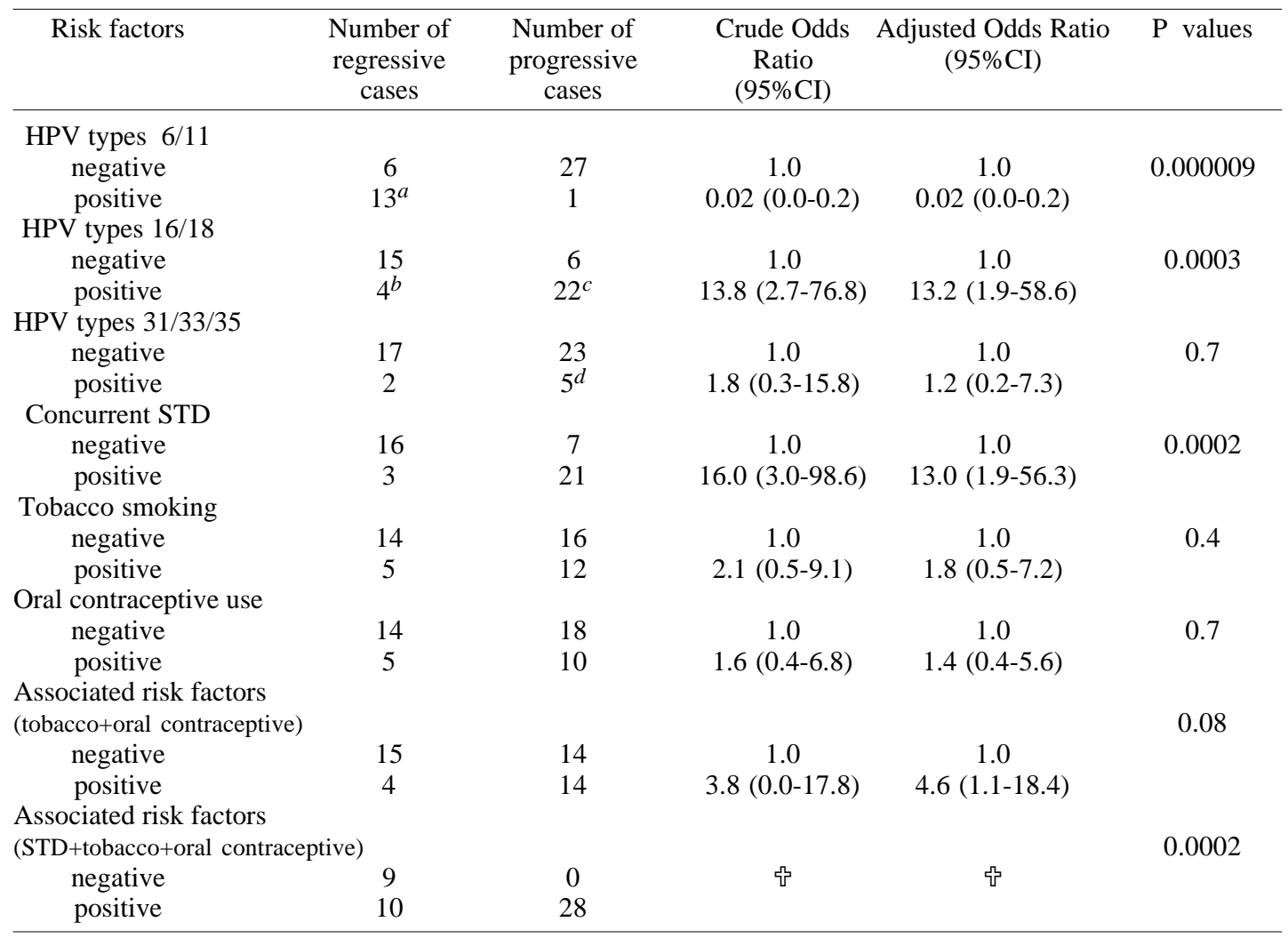

¡ Fisher exact test ( $\mathrm{P}=0.00007) ; a / b$ : 4 and $1 \mathrm{HPV}$ mixed infections, respectively; $c / d$ : 5 and $2 \mathrm{HPV}$ mixed infections, respectively.

tions, associated with high or intermediate risk HPVs. Our results reinforce the role for HPV16 and 18 in the pathogenesis of cervical cancer and indicates a relevant proportion of HPV 31,33 and 35 associated to malignancy $(29.7 \%)$.

According to Yun and Sherwood (1992), nonisotopic in situ hybridization proved to be a useful tool for distinguishing between high and low risk cervical lesions as well as a safe and rapid method for routine HPV diagnosis. Besides, it allows the simultaneous assessment of the morphological alterations associated to the studied lesion. PCR using type-specific primers confirmed the results obtained by using non-isotopic in situ hybridization (Table III), except for one sample that showed to be infected by HPV 16 by ISH and PCR revealed to be a mixed infection containing both HPV 16 and 33. No other differences were detected, indicating the satisfactory sensibility of the in situ hybridization when using biotinylated probes. Clearly, however, ISH is less sensitive than the more recently developed PCR assay, which has demonstrated even higher rates of HPV DNA (Young et al. 1989). The enhanced sensitivity of
PCR is due to both its ability to detect lower copy numbers of HPV DNA as well as to confer the possibility of evaluating a broader spectrum of HPV types, potentially all the 20 recognized genital types as opposed to the seven types usually detected by ISH (Schiffman 1994).

Multiple HPV infections were found in $22.4 \%$ (38/170) of all positive biopsies. As described by Reid et al. (1987), high rates of such infections are often detected and may be due to promiscuous sexual behaviour. But its occurrence is still not clearly associated to progression to malignancy. In our study, multiple HPV infection were not related to cancer establishment since nearly the same rates of mixed infection were detected for regressive $(26.3 \%, 5 / 19)$ and progressive lesions $(25.0 \%$, $7 / 28)\left(\mathrm{X}^{2}=0.9, \mathrm{P}>0.1\right)$.

Analysis of HPV lesions distribution in the studied population showed to be age-dependent with a continuum upward pattern from LSIL to SCC (Table I). It is also interesting to notice that HPV infections have been detected in similar rates within the three racial groups studied, with no statistical significance, in spite of the presence of a greater 
TABLE V

Risk factors associated to recurrence of Squamous Intraepithelial Lesions caused by human papillomavirus

\begin{tabular}{|c|c|c|c|c|c|}
\hline Risk factors & $\begin{array}{c}\text { Number of } \\
\text { cured } \\
\text { cases }\end{array}$ & $\begin{array}{l}\text { Number of } \\
\text { recurrent } \\
\text { cases }\end{array}$ & $\begin{array}{c}\text { Crude Odds } \\
\text { Ratio } \\
(95 \% \mathrm{CI})\end{array}$ & $\begin{array}{c}\text { Adjusted Odds } \\
\text { Ratio } \\
(95 \% \mathrm{CI})\end{array}$ & $\mathrm{P}$ values \\
\hline \multicolumn{6}{|c|}{ HPV types $6 / 11$} \\
\hline negative & 37 & 16 & 1.0 & 1.0 & \multirow[t]{2}{*}{0.007} \\
\hline positive & 42 & 3 & $0.01(0.04-0.7)$ & $0.01(0.1-0.2)$ & \\
\hline \multicolumn{6}{|c|}{ HPV types $16 / 18$} \\
\hline negative & 69 & 5 & 1.0 & 1.0 & \multirow[t]{2}{*}{0.0000001} \\
\hline positive & $10^{a}$ & $14^{b}$ & $19.3(5.0-79.9)$ & $27.4(7.2-101.2)$ & \\
\hline \multicolumn{6}{|c|}{ HPV types $31 / 33 / 35$} \\
\hline negative & 72 & 17 & 1.0 & 1.0 & \multirow[t]{2}{*}{0.8} \\
\hline positive & $7^{c}$ & 2 & $1.2(0.16-7.3)$ & $1.2(0.6-2.2)$ & \\
\hline \multicolumn{6}{|c|}{ Concurrent STD } \\
\hline negative & 77 & 13 & 1.0 & 1.0 & \multirow[t]{2}{*}{0.0002} \\
\hline positive & 2 & 6 & $17.8(2.8-145.1)$ & $17.2(7.2-32.9)$ & \\
\hline \multicolumn{6}{|c|}{ Tobacco smoking } \\
\hline negative & 68 & 15 & 1.0 & 1.0 & \multirow[t]{2}{*}{0.7} \\
\hline positive & 11 & 4 & $1.7(0.4-6.8)$ & $2.0(0.1-0.4)$ & \\
\hline \multicolumn{6}{|c|}{ Oral contraceptive use } \\
\hline negative & 60 & 16 & 1.0 & 1.0 & \multirow[t]{2}{*}{0.6} \\
\hline positive & 19 & 3 & $0.6(0.12-2.5)$ & $0.4(0.2-1.1)$ & \\
\hline \multicolumn{6}{|c|}{$\begin{array}{l}\text { Associated risk factors } \\
\text { (tobacco+oral contraceptive) }\end{array}$} \\
\hline negative & 73 & 12 & 1.0 & 1.0 & \multirow[t]{2}{*}{0.002} \\
\hline positive & 6 & 7 & $34.9(6.1-262.9)$ & $7.0(3.0-15.2)$ & \\
\hline \multicolumn{6}{|c|}{$\begin{array}{l}\text { Associated risk factors } \\
\text { (STD+tobacco+oral contraceptive) }\end{array}$} \\
\hline negative & 41 & 2 & 1.0 & 1.0 & \multirow[t]{2}{*}{0.0000004} \\
\hline positive & 10 & 17 & $9.2(3.6-25.3)$ & $9.0(3.4-24.2)$ & \\
\hline
\end{tabular}

$a / c: 7$ and $5 \mathrm{HPV}$ mixed infections, respectively; $b: 6 \mathrm{HPV}$ mixed infection.

number of white women showing SILs. Similar results have been previously described (Cavalcanti et al. 1994) and have to be further investigated.

Evaluation of the natural history of HPV infection indicated high rates of progression (30.4\%) and persistence (48.9\%). Regressing lesions have been demonstrated in $20.7 \%$ of the cases. Syrjanen (1989) described similar rates, although progression rates were lower $(20 \%)$ than those here described. Kataja et al. (1992), during a follow-up of eight years, showed that nearly $65 \%$ of the HPV infections have regressed spontaneously while $14 \%$ of the patients progressed to in situ carcinoma or SCC. These results are considerably different from ours. In fact, HPV types distribution in Europe are also quite different from Brazil, where oncogenic HPV 18 are commonly detected in HSILs and SCCs (Cavalcanti et al. 1994). This could explain such poor prognosis of LSILs in our country. Other authors (Kristiansen et al. 1994) also related an association of HPV 18 and poor prognosis, for which there is some support, associated to efficient and fast neoplastic transformation promoted by HPV 18 in vivo and in vitro (Walker et al. 1989, Barnes et al. 1990).
In this study we also detected a high prevalence of HPV types 31,33 and 35 (29.7\%), contrasting to other countries where they have been demonstrated in less than $10 \%$ of the premalignant and malignant lesions (Lowy et al. 1994). Such diverse pattern of HPV types infecting Brazilian women could contribute to the high rates of progression recorded by us, showing that one third of the women with LSIL will develop cancer and $20 \%$ of the treated lesions will recur. Confirming these suggestion, we showed that $78.6 \%(22 / 28$, COR13.8, $\mathrm{P}=0.0003$ ) of the progressive lesions presented oncogenic HPVs 16 and 18, contrasting with regressing cases displayed predominantly benign types (68.4\%, COR 0.02, $\mathrm{P}=0.000009)$. Our results are in agreement with those of Kataja et al. (1993), lesions caused by low risk types may undergo spontaneous regression while those infected by high risk HPVs show little evidence of regression. Nevertheless, although occurring at high prevalences in malignant lesions, HPVs 31, 33 and 35 did not present statistical association to progression or recurrence. These apparently controversial results may be due to the small number of progressive lesions evaluated. Hence, further studies are 
required to analyze their real oncogenic potential in cervical lesions.

As described in Table IV, concurrent STD were significantly related to progressive lesions and even after adjustment it has showed to be significantly associated to progression (Adjusted OR 13.0, $\mathrm{P}=0.0002$ ). STDs probably contributed to progression of the HPV lesions by depressing local immunity of the genital tract. Although poorly understood, host cellular defence mechanisms seem to play an important role in controlling HPV infection. Patients with cellular immune deficiencies (such as HIV-positive ones) have higher rates of HPV infection and are more susceptible to develop high grade SILs (Ho et al. 1994). In accordance to our findings, Meekin et al. (1992) described a link between previous or current STDs and progression to HPV-induced high grade lesions, proposing that these infections might act as markers for developing SILs. Other studies suggested that other cervical infections may interact with HPV increasing the risk of developing HSILs (Koutsky et al. 1992).

The effect of OC use on cervical carcinogenesis has been widely investigated. The incidence of cervical carcinoma was found to be higher among women who had used OC compared to non-users. Stern et al. (1977) have suggested that the progression rate might be higher in OC users than in other women. Nevertheless, we have not found any significant correlation when statistical significance were analyzed (AOR1.4, $\mathrm{P}=0.7$ ). These results are in agreement with those from other authors (Davidson et al. 1994).

Regarding the relationship between smoking and cervical cancer, studies indicated a slight increase in the risk of the disease among smokers, attributed to a local impairment of cell-mediated immunity, but the effect was small (Vessey 1986). In our study no correlation could be demonstrated. In fact, our preliminary results pointed out that cigarette smoking and $\mathrm{OC}$ use were not related to cancer progression, in accordance to results from Van Doornum et al. (1993) and Eluf-Neto et al. (1994). But when these factors were associated, differences were observed in a great number of smokers+OC users showing progressive lesions, when compared to the other groups (only OC users, only smokers, non-OC user/non-smoker) (AOR 4.6, $\mathrm{P}=0.08$ ). Association of three study factors (STDs+cigarette+OC) has shown that $100 \%$ of the progressive cases were related to at least one of the analyzed risk factors, while only $47.3 \%$ of the regressing lesions presented them $(\mathrm{P}=0.0002)$. These results are similar to those described by Vandenvelde and Van Beers (1993) who found that well-known risk factors for cervical cancer seem to co-operate with HPV DNA in order to increase the risk of malignant progression. Molecular mechanisms could explain the fact: HPV infection with high risk types and consequent synthesis of oncoproteins E6 and E7 would not be sufficient for malignant transformation. When other factors increasing the risk of mutational events and transformation are associated, the probability of cancer development increases.

From the 98 treated patients, 19 (19.4\%) showed recurrence (Table V). Twenty out of the 98 treated and cured women were HPV negative (20.4\%). Hence, from the 78 HPV-positive lesions submitted to treatment, 19 recurred $(24.4 \%)$. In these recurrent lesions, $73.7 \%$ (14/19) of the cases presented oncogenic HPV types (OR 27.4, $\mathrm{P}=0.0000001)$. In relation to risk factors, the association was the same seen in progressive cases: concurrent STDs (AOR 17.2, $\mathrm{P}=0.0002$ ) but neither smoking nor OC use were associated to recurrence $(\mathrm{P}>0.1)$. Association of the three parameters were related to recurrence (AOR 9.0, $\mathrm{P}=0.0000004)$, reinforcing the idea of co-operation between factors increasing the risk of developing CINs and cancer. Some authors described that $90 \%$ of the patients achieved a two-year cure by using treatment procedures similar to ours: cauterization and conization (Yliskoski et al. 1991), contrasting to the $80 \%$ of cure showed by us in a five-year study. These observations could be attributed to the different periods of analysis, or to the higher frequency of oncogenic HPVs detected in our patients what could be responsible for these lower efficiency in achieving cure.

In our study, we present the results of a retrospective five-year analysis. Despite the adjustment for possible confounding factors, oncogenic HPV types 16 and 18 and history of STD showed to be significantly associated to progression to cancer and to unsuccessful treatment of HPV-induced lesions. Smoking and the use of OC did not show relation to these events but when they were associated, a significant co-operative role in both progression and recurrence were demonstrated and thus a poor prognosis for women presenting SILs were described in Brazil.

\section{ACKNOWLEDGEMENTS}

To Dr Luiza L Villa for kindly providing the HPV primers for PCR. To Edson Alves de Souza and Vera Lúcia S Peixoto for their technical assistance.

\section{REFERENCES}

Barnes W, Woodworth C, Wagooner S 1990. Rapid dysplastic transformation of human genital cells by human papillomavirus type 18. Gynecol Oncol 38 : 343-346.

Bethesda system for reporting cervical/vaginal cytologic diagnosis 1993. Acta Cytol 37: 115-124. 
Cavalcanti SMB, Frugulhetti ICP, Passos MRL, Fonseca MEF, Oliveira LHS 1994. Prevalence of human papillomavirus DNA in female cervical lesions from Rio de Janeiro, Brazil. Mem Inst Oswaldo Cruz 89: 575-580.

Davidson M, Schnitzer PG, Bulkow LR, Schloss ML, Fitzgerald MA, Knight JA, Kiviat NB, Toomey KE, Reeves WC, Schmidt DS, Stamm WE 1994. The prevalence of cervical infection with human papillomaviruses and cervical dysplasia in Alaska native women. J Infect Dis 169: 792-800.

De Villiers EM 1989. Heterogeneity of human papillomavirus group. J Virol 63: 4898-4903.

Eluf-Neto J, Booth M, Muñoz N, Bosch F, Meijer CLM, Walboomers JM 1994. Human papillomavirus and invasive cervical cancer in Brazil. Brit J Cancer 69: 114-119.

Ho GYF, Burk RD, Fleming I, Klein RS 1994. Risk of genital human papillomavirus infection in women with human immunodeficiency virus-induced immunosuppression. Int J Cancer 56: 788-792.

Kataja V, Syrjanen S, Mantijarvi R 1992. Prognostic factors in cervical human papillomavirus infections. Sex Transm Dis 19: 154-160.

Kataja V, Syrjanen S, Yliskoski M 1993. Risk factors associated with cervical human papillomavirus infections: a case-control study. Am J Epidem 138: 735-745.

Kiviat NB, Koutsky LA, Paavonen JA 1989. Prevalence of genital papillomavirus infection among women attending a college student clinic or a sexually transmitted disease clinic. J Infec Dis 159: 293-302.

Koutsky LA, Holmes KK, Crichtlow CW, Stevens CE, Paavonen J, Beckman AM, DeRouen TA, Galloway DA, Vernon CT, Kiviat NB 1992. A cohort study of the risk of cervical intraepithelial neoplasia grade 2 or 3 in relation to papillomavirus infection. $N$ Engl J Med 18: 1272-1278.

Kristiansen E, Jenkins A, Kristiansen G, Ask E, Kaern J, Abeler J, Lindqvist BH, Tropé C, Kristiansen BE 1994. Human papillomavirus infection in Norwegian women with cervical cancer. APMIS 102: 122128.

Lowy DR, Kirnbauer R, Schiller JT 1994. Genital human papillomavirus infection. Proc Nat Acad Sci USA 91: 2436-2440.

Meekin GE, Sparrow MJ, Fernwicke RJ, Tobias M 1992. Prevalence of genital human papillomavirus infection in Wellington women. Genitorin Med 68: 228232.

Reid R, Greenberg M, Jenson AB, Stanhope R, Hershman VR, Smith JP, Lancaster WD 1987. Sexually transmitted papillomavirus infections. I. The anatomic distribution and pathologic grade of neo- plastic lesions associated with different viral tyes. Am J Obstet Gynecol 156: 212-222.

Roman A, Fife KH 1989. Human papillomaviruses: are we ready to type? Clin Microbiol Rev 2: 166-190.

Schiffman MH 1994. Epidemiology of cervical human papillomavirus infections. Cur Microbiol Immunol 186: 56-78.

Stern E, Forsythe AB, Youkles L, Coffelt CF 1977. Steroid contraceptive use and cervical cancer: increased risk of progression. Science 196: 1460-1463.

Syrjanen KJ 1989. Epidemiology of human papillomavirus (HPV) infections and their association with genital squamous cell cancer. APMIS 97: 957-970.

Syrjanen SM 1990. Basic concepts and practical applications of recombinant DNA techniques in the detection of human papillomavirus (HPV) infections. APMIS 98: 95-110.

Vandenvelde C, Van Beers D 1993. High risk genital papillomaviruses and degree of dysplastic changes in the cervix. J Med Virol 39: 273-277.

Vandenvelde C, Vestraeten M, Van Beers 1990. Fast multiplex polymerase chain reaction on boiled clinical samples for rapid viral diagnosis. J Virol Methods 30: 215-227.

Van Doornum GJJ, Van den Hoek JAR, Van Ameijden EJC, Van Haastrecht HJA, Roos MTL, Henquet CJM, Quint WGV, Coutinho RA 1993. Cervical HPV infection among HIV-infected prostitutes addicted to hard drugs. J Med Virol 41: 185-190.

Vessey MP 1986. Epidemiology of cervical cancer: role of hormonal factors, cigarette smoking and occupation. Banbury Report Series 21: 29-43.

Yliskoski M, Saarikoski S, Syrjanen K 1991. Conization for CIN associated to human papillomavirus infection. Arch Gynecol Obstet 249: 59-65.

Young LS, Bevan IS, Jonhson MA, Blomfield PI, Bromigde T, Maitland NJ, Woodman CBJ 1989. The polymerase chain reaction: a new epidemiological tool for investigating cervical human papillomavirus infection. Brit Med J 298: 14-18.

Yun K, Sherwood MJ 1992. In situ hybridization at light and electron microscopic levels: identification of human papillomavirus nucleic acids. Pathol 24: 9198.

Walker J, Bloss JD, Liao SY, Berman M, Berhen S, Wilczynski SP 1989. Human papillomavirus genotype as a prognostic indicator in carcinoma of the uterine cervix. Obstet Gynecol 74: 781-785.

Woodworth CD, Doniger J, Di Paolo JA 1989. Immortalization of human foreskin keratinocytes by various human papillomavirus DNAs correspond to their association with cervical carcinoma. J Virol 63: 159164. 